\title{
Relationship between vitamin $D$ and gestational diabetes in overweight or obese pregnant women may be mediated by adiponectin
}

Aya Mousa ${ }^{1}$, Sally K Abell ${ }^{1}$, Soulmaz Shorakae ${ }^{1}$, Cheryce L Harrison ${ }^{1}$, Negar Naderpoor ${ }^{1}$, Danielle Hiam $^{2}$, Alba Moreno-Asso ${ }^{2}$, Nigel K Stepto ${ }^{1,2}$, Helena J Teede ${ }^{1}$, Barbora de Courten ${ }^{1}$

${ }^{1}$ Monash Centre for Health Research and Implementation (MCHRI), School of Public Health and Preventive Medicine, Monash University; Locked Bag 29, Clayton, VIC 3168, Melbourne, Australia

${ }^{2}$ Institute of Sport, Exercise and Active Living, Victoria University; PO Box 14428, VIC 8001, Melbourne, Australia

\section{Correspondence:}

A/Prof. Barbora de Courten, MD PhD MPH FRACP

Monash Centre for Health Research and Implementation (MCHRI), School of Public health and Preventive Medieine, Monash University

Level 1, 43-51 Kanooka Grove, Clayton,

Melbourne, VIC 3168, Australia

Telephone: +61385722651

Email: barbora.decourten@monash.edu

Keywords: vitamin D, adipokines, pregnancy, cardiometabolic risk factors, gestational diabetes mellitus.

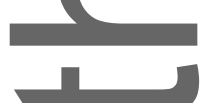

Abbreviations: 1,25(OH) $)_{2} \mathbf{D}_{3}, 1,25$-dihyroxyvitamin $\mathrm{D}_{3} ; \mathbf{2 5}(\mathrm{OH}) \mathrm{D}, 25$-hydroxyvitamin $\mathrm{D}$; BMI, body mass index, ELISA, enzyme linked immunosorbent assays; GDM, gestational diabetes mellitus; HDL/LDL, high-/ low- density lipoprotein; HMW, high-molecular weight; IL-6, interleukin-6; MCP-1, monocyte-chemoattractant protein-1; OGTT, oral glucose tolerance test; PCOS, polycystic ovary syndrome; PTB, preterm birth; RCT, randomized controlled trial; VDR, vitamin D receptor.

This is the author manuscript accepted for publication and has undergone full peer review but has not been through the copyediting, typesetting, pagination and proofreading process, which may lead to differences between this version and the Version of Record. Please cite this article as doi:

10.1002/mnfr.201700488.

This article is protected by copyright. All rights reserved. 


\section{ABSTRACT}

Scope: Maternal vitamin D deficiency has been implicated in adverse pregnancy outcomes.

However, the association between vitamin D and inflammation, particularly adipokines, remains unexplored in pregnancy.

Methods and Results: In 102 overweight or obese pregnant women at high-risk of gestational diabetes (GDM), we investigated relationships between maternal 25hydroxyvitamin $(25(\mathrm{OH}) \mathrm{D})$ concentrations at 12-15 weeks gestation (baseline) and serum lipids, inflammatory markers, novel adipokines (omentin-1, visfatin, high molecular weight (HMW)-adiponectin), and subsequent pregnancy outcomes (GDM, preeclampsia, preterm birth [PTB]). After adjustment for maternal factors (age, BMI, parity, ethnicity, and smoking status), baseline $25(\mathrm{OH}) \mathrm{D}$ concentrations were inversely associated with total cholesterol and triglycerides, and positively associated with HMW-adiponectin. Higher baseline 25(OH)D concentrations were associated with decreased fasting and 1-hour post-OGTT glucose and reduced risk of GDM at 26-28 weeks, as well as with longer gestation and reduced risk of PTB upon additional adjustment for caesarean section. Adding HMW-adiponectin to the multivariable models attenuated most associations, and HMW-adiponectin was a significant predictor in the models.

Conclusion: Our findings suggest that lower maternal 25(OH)D concentrations in overweight/obese pregnant women at high-risk of GDM are associated with increased cardiometabolic risks during pregnancy and adverse pregnancy outcomes, and that these associations may be mediated by HMW-adiponectin. 


\section{Graphical Abstract -Text}

This study investigated associations between vitamin D concentrations in 102 women at 1215 weeks gestation and cardiometabolic risk factors including novel adipokines (omentin-1, visfatin, high molecular weight (HMW)-adiponectin) as well as subsequent pregnancy outcomes. Lower maternal vitamin D levels were associated with poorer lipid profiles, suboptimal inflammatory and adipokine profiles, and poorer glucose metabolism later in pregnancy, as well as adverse pregnancy outcomes including gestational diabetes and preterm birth. These associations appeared to be mediated by HMW-adiponectin.

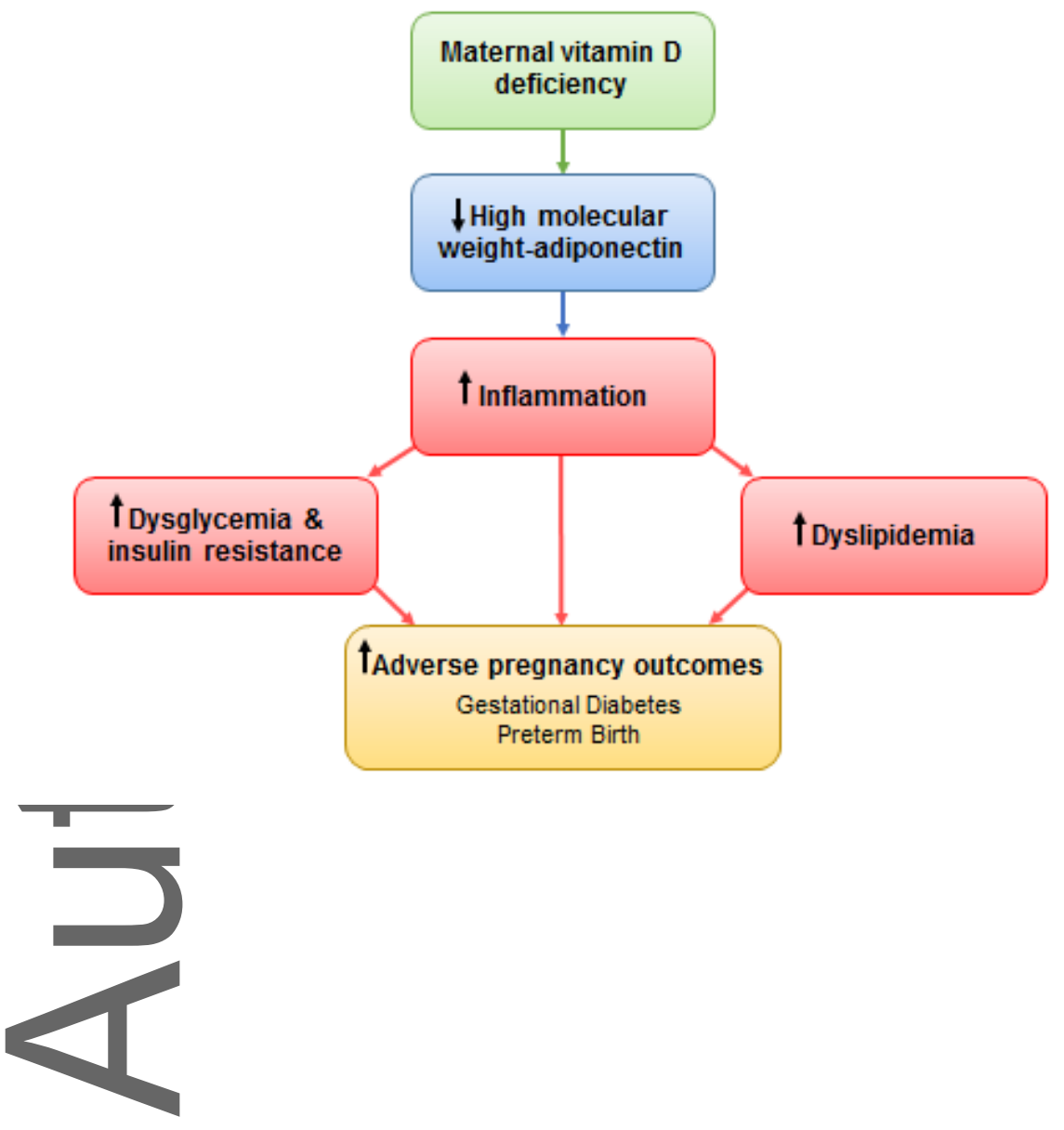

This article is protected by copyright. All rights reserved. 


\section{Introduction}

Vitamin D deficiency is prevalent worldwide, and is common during pregnancy [1]. The Dource primary source of vitamin D is through sun exposure to ultraviolet B radiation. Therefore, increased rates of obesity and sedentary indoor lifestyles, as well as sun avoidance behaviors and use of sunscreen to prevent skin cancer have contributed to the rise in vitamin D deficiency [1]. Moreover, few foods are naturally high in vitamin D or are vitamin D-fortified [1]. Although there is currently no consensus regarding optimal vitamin D levels during pregnancy, the Institute of Medicine [2] and National Institutes of Health [3] suggest that circulating 25 -hydroxyvitamin $\mathrm{D}(25(\mathrm{OH}) \mathrm{D})$ concentrations $<50$ and $<25 \mathrm{nmol} / \mathrm{l}$ are considered deficient and severely deficient, respectively. It is therefore concerning that 40 $98 \%$ of pregnant women globally have $25(\mathrm{OH}) \mathrm{D}$ concentrations $<50 \mathrm{nmol} / 1$ and $15-84 \%$ have concentrations $<25 \mathrm{nmol} / 1[1]$.

Recent evidence suggests that vitamin D deficiency may contribute to unfavorable cardiometabolic profiles during pregnancy and adverse pregnancy outcomes [4, 5]. The nuclear vitamin D receptor (VDR) and metabolizing enzyme, $1 \alpha$-hydroxylase, are present in the decidua, placenta, ovary, and endometrium [6]. In vitro studies have shown that active vitamin $\mathrm{D}\left(1,25(\mathrm{OH})_{2} \mathrm{D}_{3}\right)$ has potent anti-inflammatory properties [7], and directly activates transcription of the insulin receptor gene [8], as well as regulating transcription of genes associated with placental invasion, normal implantation, and angiogenesis [9]. Therefore, vitamin D deficiency may lead to increased inflammation and decreased insulin action, which could contribute to increased risk of adverse pregnancy outcomes including gestational diabetes mellitus (GDM), preeclampsia, and preterm birth (PTB). Indeed, observational studies have reported inverse associations between maternal 25(OH)D concentrations and cardiometabolic risk factors during pregnancy, including insulin resistance [10], dysglycemia 
[11], dyslipidemia [12], hypertension [13], and inflammation [14, 15]. Prospectively, maternal vitamin D deficiency has been linked to increased risk of GDM [16], pre-eclampsia [17], and PTB [18]; however results are inconsistent [19-21]. Moreover, most existing studies are limited by small sample sizes and lack of adjustment for potential confounders including obesity, parity, ethnicity, and smoking status.

It is proposed that maternal vitamin D deficiency may contribute to increased cardiometabolic risk and adverse pregnancy outcomes via pro-inflammatory pathways [22] and there is growing interest in the potential role of adipokines [23]. Studies have reported associations between vitamin D deficiency and altered adipokine concentrations in patients with type 2 diabetes [24] and polycystic ovary syndrome (PCOS) [25]; however these relationships have not been explored in pregnancy. To our knowledge, no previous studies have examined associations between vitamin $\mathrm{D}$ and novel adipokines including visfatin or omentin- 1 in preghancy, and few have examined high-molecular weight (HMW) adiponectin [26]. These adipokines are believed to be involved in the pathophysiology of adverse pregnancy outcomes including GDM $[16,23]$, thus further investigation of the relationship between vitamin $\mathrm{D}$ deficiency and these adipokines in pregnancy is warranted.

We aimed to address existing knowledge gaps by examining: (i) associations between $25(\mathrm{OH}) \mathrm{D}$ concentrations and serum lipids, inflammatory markers, and novel adipokines in early pregnancy (12-15 weeks gestation); (ii) associations between $25(\mathrm{OH}) \mathrm{D}$ concentrations in early pregnancy (12-15 weeks gestation) and risk of subsequent adverse pregnancy outcomes (GDM at 26-28 weeks gestation, preeclampsia during pregnancy, and PTB at delivery), and (iii) whether these associations may be mediated by circulating adipokine concentrations. 


\section{Materials and methods}

\subsection{Study design and participants}

This study involved post-hoc analyses of pre-collected bio-banked serum samples from a large randomized controlled trial (RCT) in high risk pregnancies [27]. The RCT aimed to prevent excess gestational weight gain in women identified as high risk for GDM based on a validated risk prediction tool [28]. Methods for the RCT have been reported previously [27]. Briefly, 228 women were recruited from three large tertiary teaching hospitals in Melbourne, Australia (2008-2010). Women were included in the study if they met the following criteria: age $>18$ years old; with a singleton pregnancy; $<15$ weeks gestation; overweight (body mass index $(\mathrm{BMI})>25 \mathrm{~kg} / \mathrm{m}^{2}$ or $>23 \mathrm{~kg} / \mathrm{m}^{2}$ if high risk ethnicity [29]) or obese (BMI $\geq 30 \mathrm{~kg} / \mathrm{m}^{2}$ ) at baseline (12-15 weeks gestation); with an increased risk of GDM (score $\geq 3$ based on risk prediction tool [28]). Exclusion criteria included a BMI $\geq 45 \mathrm{~kg} / \mathrm{m}^{2}$, non-English speaking women, known pre-existing type 1 or type 2 diabetes, or any other chronic medical condition. The study population was well characterized including demographics, antenatal characteristics, and longitudinal evaluation of pregnancy outcomes. Women were randomized to an antenatal lifestyle intervention or a control group. Samples from the control group $(n=102)$, who were assigned to routine antenatal care with standard dietary and lifestyle advice, were analyzed in the current study.

\subsection{Data collection}

As previously reported [27], demographic characteristics were collected using a baseline questionnaire. BMI was calculated at the baseline visit (12-15 weeks) by a registered nurse independent to the research staff. Fasting venous blood samples were drawn at 12-15 weeks gestation for all participants. Serum was stored in multiple aliquots under sterile conditions at 
$-80^{\circ} \mathrm{C}$. GDM screening was performed at $26-28$ weeks gestation with an oral glucose

tolerance test (OGTT). GDM was diagnosed based on the Australasian Diabetes in Pregnancy Society (ADIPS 1998) criteria at the time of the study (fasting glucose $\geq 5.5 \mathrm{mmol} / 1 \mathrm{and} /$ or 2 hour glucose $\geq 8.0 \mathrm{mmol} / \mathrm{l}$ ) [30]. Maternal and obstetric outcomes were obtained from the Birthing Qutcomes System database, which is commonly used for research purposes $[28,31]$ and includes standardized information for routine reporting of perinatal data in Victoria, Australia. Pregnancy outcomes assessed in this study included preeclampsia diagnosed based on the Royal Australia New Zealand College of Obstetricians and Gynecologists guidelines [32], and PTB defined as $<37$ weeks gestation [32]. The primary study was approved by the Monash Health Research Advisory and Ethics Committee (Project ID: 07216C) and all participants gave written informed consent [27].

\subsection{Biochemical analyses}

Fasting serum lipids (triglycerides, total cholesterol, and high- and low-density lipoprotein cholesterol [HDL, LDL]) as well as plasma glucose, and 25(OH)D concentrations were analyzed by accredited commercial pathology providers (Melbourne Pathology and Monash Pathology, Melbourne, Australia). Lipids and glucose were analyzed using a Hitachi modular analyzer (Roche Diagnostics, Mannheim, Germany) and 25(OH)D concentrations were measured using direct competitive chemiluminescent immunoassays (CLIA) (DiaSorin Inc., MN, USA) with inter- and intra-assay coefficients of variation (CVs) of $<10 \%$ and $<4 \%$, respectively. Serum inflammatory biomarkers and adipokines were analyzed using sandwichtype enzyme linked immunosorbent assays (ELISA). All assays were performed in duplicate according to manufacturers' instructions. Pilot studies were performed to calculate dilutions and ensure concentrations fit within the standard curve for each assay. Samples with values outside the standard curve were excluded from analysis for that specific biomarker. Analyte 
concentrations were calculated from best-fit standard curves multiplied by the dilution factor to determine target protein concentrations. HMW-adiponectin was measured using the ALPCO ELISA (47-ADPHU-E01; sensitivity= $0.019 \mathrm{ng} / \mathrm{ml}$ ), which required pre-treatment with protease II to selectively digest low- and middle-molecular weight adiponectin. HMWadiponectin was measured instead of total adiponectin in this study as it is considered the active form of adiponectin and a more sensitive marker of glucose intolerance and insulin resistance than total adiponectin $[33,34]$. Visfatin was measured using the BioVendor ELISA (RAG004R; sensitivity=30 pg/ml), and Omentin-1 was measured using the Millipore ELISA (EZH0MNTN1-29K; sensitivity= $0.23 \mathrm{ng} / \mathrm{ml}$ ). Interleukin-6 (IL-6) was measured using the Abcam high sensitivity ELISA (ab46042; sensitivity $=0.81 \mathrm{pg} / \mathrm{ml}$ ). Monocyte chemoattractant protein-1 (MCP-1) was measured using the Picokine ELISA (EK0441; sensitivity <1 pg/ml). Inter- and intra-assay CVs for all biomarkers were $<10 \%$.

\subsection{Statistical analyses}

Statistical analyses were performed using Stata Version 12.0 (StatCorp LP, USA). Participant characteristics and clinical and biochemical parameters are presented as mean \pm standard deviation (SD), frequencies (n [\%]), or median (interquartile range [IQR]) for non-normally distributed variables, unless otherwise indicated. Variables which were not normally distributed were logarithmically transformed to the base 10 to approximate normality prior to analysis. Univariable associations between $25(\mathrm{OH}) \mathrm{D}$ concentrations and continuous and categorical outcomes were assessed using Pearson correlations and simple logistic regression, with results presented as correlation coefficients for continuous outcomes or odds ratios with $95 \%$ confidence intervals for binary outcome variables. Differences in mean $25(\mathrm{OH}) \mathrm{D}$ concentrations between groups (eg: women with or without GDM) were assessed using independent Student's $t$-tests. Variables which were statistically significant on univariable 
analyses $(\mathrm{p}<0.05)$ were included as covariates in multiple linear and logistic regression models. In first model, we adjusted for predetermined maternal factors considered to be clinically relevant to the outcomes, including: age, BMI, parity, ethnicity, and smoking status. In the second model, we performed exploratory analyses to further adjust for adipokines which were significantly associated with the outcomes of interest to examine their potential mediatory role. Findings were considered statistically significant at a two-tailed level of $\mathrm{p}<0.05$.

\section{Results}

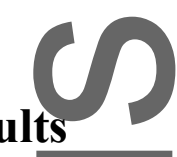

\subsection{Sample characteristics}

Demographic, biochemical, and clinical outcome data are presented in Table 1. The mean age of participants was $31.9 \pm 4.5$ years (mean \pm SD) (range $=25-43$ years), with a median BMI of $29(26-34) \mathrm{kg} / \mathrm{m}^{2}$ (median [IQR]) at baseline (12-15 weeks). Mean 25(OH)D concentration of participants at baseline was $48.0 \pm 16.0 \mathrm{nmol} / \mathrm{l}$, with over half $(\mathrm{n}=53 ; 52 \%)$ being classified as vitamin D-deficient $(25(\mathrm{OH}) \mathrm{D} \leq 50 \mathrm{nmol} / \mathrm{l})$. At $26-28$ weeks gestation, 25 of the 102 women $(24.5 \%)$ were diagnosed with GDM. Four $(3.9 \%)$ of the 102 women were diagnosed with preeclampsia during the course of their pregnancy, and six women $(5.8 \%)$ experienced a PTB ( $<37$ weeks gestation).

\subsection{Cross-sectional associations with serum $25(\mathrm{OH}) \mathrm{D}$ concentrations}

Results of cross-sectional univariable analyses at baseline are presented in Table 2.

Serum $25(\mathrm{OH}) \mathrm{D}$ concentrations were not associated with maternal characteristics including age $(\mathrm{p}=0.2)$ or $\mathrm{BMI}(0=0.1)$ (Table 2$)$ and there were no differences in $25(\mathrm{OH}) \mathrm{D}$ concentrations by parity $(p=0.8)$, ethnicity $(p=0.4)$, or smoking status $(p=0.3)$ (data not shown). 
At baseline, serum 25(OH)D concentrations were inversely associated with total cholesterol $(\mathrm{r}=-0.22 \mathrm{mmol} / \mathrm{l}, \mathrm{p}=0.03)$, triglycerides $(\mathrm{r}=-0.30 \mathrm{mmol} / \mathrm{l}, \mathrm{p}=0.003)$, and IL-6 concentrations $(\mathrm{r}=-0.20 \mathrm{pg} / \mathrm{ml}, \mathrm{p}=0.048)$, and positively associated with $\mathrm{HMW}$-adiponectin $(\mathrm{r}=0.27 \mu \mathrm{g} / \mathrm{ml}$, $\mathrm{p}=0.007)$. There were no associations between $25(\mathrm{OH}) \mathrm{D}$ concentrations and HDL or LDL cholesterol or the other inflammatory markers and adipokines measured including MCP-1, omentin-1, and visfatin (all p>0.05; Table 2).

Results of multivariable linear regression analyses are presented in Table 3A. After adjusting for maternal factors age, BMI, parity, ethnicity, and smoking status, 25(OH)D concentrations remained inversely associated with total cholesterol $(\beta=-0.23, p=0.04)$, and triglycerides $(\beta=-$ $0.28, \mathrm{p}=0.02)$, and positively associated with HMW-adiponectin $(\beta=0.25, \mathrm{p}=0.02)$; however the association with IL-6 was no longer significant ( $\mathrm{p}=0.6$; Table $3 \mathrm{~A}$ ).

\subsection{Longitudinal associations with serum $25(\mathrm{OH}) \mathrm{D}$ concentrations}

Results of longitudinal univariable analyses are presented in Table 2. Baseline 25(OH)D concentrations (at 12-15 weeks) were associated with glycemic outcomes at 26-28 weeks, including fasting glucose $(\mathrm{r}=-0.35 \mathrm{mmol} / \mathrm{l}, \mathrm{p}=0.0008)$ and 1-hour post-OGTT glucose levels $(\mathrm{r}=-0.22 \mathrm{mmol} / \mathrm{l}, \mathrm{p}=0.04)$, but were not associated with 2-hour post-OGTT glucose levels $(\mathrm{p}=0.1$; Table 2). Women who developed GDM at 26-28 weeks $(\mathrm{n}=25)$ had a significantly lower $25(\mathrm{OH}) \mathrm{D}$ concentration at baseline compared with women who did not develop GDM $(\mathrm{n}=77 ; 42.1 \pm 14.7$ versus $49.8 \pm 16.1 \mathrm{nmol} / \mathrm{l}$, respectively, $\mathrm{p}=0.03)$. In simple logistic regression, higher $25(\mathrm{OH}) \mathrm{D}$ concentrations at baseline were associated with a reduced risk of GDM at 26-28 weeks gestation (OR [95\%CI] $=0.97$ [0.94-0.99], $\mathrm{p}=0.04$; Table 2).

Baseline 25(OH)D concentrations were also positively associated with length of gestation $(r=0.32$ weeks, $p=0.001$; Table 2$)$. A trend was observed for lower baseline 25(OH)D concentrations in women who subsequently had a PTB $(n=6)$ compared to women who 
reached term $(n=96)$; however this did not reach statistical significance (36.6 versus 48.3 $\mathrm{nmol} / 1$, respectively, $\mathrm{p}=0.08$ ). In simple logistic regression, a trend was observed for an association between baseline $25(\mathrm{OH}) \mathrm{D}$ concentrations and risk of PTB $(\mathrm{OR}[95 \% \mathrm{CI}]=0.95$ $[0.90-1.00], p=0.09)$. There were no associations between $25(\mathrm{OH}) \mathrm{D}$ concentrations and preeclampsia $(\mathrm{p}=0.6$; Table 2$)$ or caesarean section $(\mathrm{p}=0.7$; Table 2$)$.

After adjustment for maternal factors age, BMI, parity, ethnicity, and smoking status, baseline $25(\mathrm{OH}) \mathrm{D}$ concentrations remained inversely associated with fasting and 1-hour postOGTT glucose levels at 26-28 weeks $(\beta=-0.38, \mathrm{p}=0.002$, and $\beta=-0.26, \mathrm{p}=0.02$, respectively; Table 3A). Similarly, baseline $25(\mathrm{OH}) \mathrm{D}$ concentrations remained associated with a reduced risk of GDM at 26-28 weeks after adjustment for maternal factors $(\mathrm{OR}[95 \% \mathrm{CI}]=0.96[0.93$ 0.99 ], $\mathrm{p}=0.02$; Table $3 \mathrm{~B})$. The positive association between $25(\mathrm{OH}) \mathrm{D}$ concentration and length of gestation also persisted in the multivariable model $(\beta=0.33, p=0.005$; Table $3 \mathrm{~A})$. A non-significant trend was observed for an association between higher baseline 25(OH)D concentrations and reduced risk of PTB after adjustment for maternal factors $(p=0.06$; data not shown), which became significant after additional adjustment for caesarean section (OR $[95 \% \mathrm{CI}]=0.89[0.79-0.99], \mathrm{p}=0.03$; Table $3 \mathrm{~B})$.

\subsection{Exploratory analysis of potential role of adipokines}

Results of exploratory analyses are presented in Table 3. HMW-adiponectin was the only adipokine associated with the outcome measures on univariable analyses (all $p<0.05$; data not shown), hence it was added as a covariate in the multivariable models. In cross-sectional analyses, after adjusting for HMW-adiponectin and maternal factors age, BMI, parity, ethnicity and smoking status, the associations between $25(\mathrm{OH}) \mathrm{D}$ concentrations and total cholesterol and triglycerides at baseline were no longer significant $(p=0.08$ and $p=0.1$, 
respectively; Table 3A). HMW-adiponectin was the only significant predictor in the model for triglycerides at baseline $(\mathrm{p}=0.005)$.

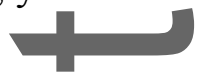

In longitudinal analyses, baseline $25(\mathrm{OH}) \mathrm{D}$ concentrations remained associated with fasting glucose at 26-28 weeks after adjustment for HMW-adiponectin in addition to maternal factors $(\beta=-0.27, \beta=0.03$; Table 3A). However, associations with 1-hour post-OGTT glucose levels as well as GDM risk were attenuated ( $\mathrm{p}=0.2$ and $\mathrm{p}=0.1$, respectively; Table 3$)$. In these models, HMW-adiponectin was the only significant predictor associated with risk of GDM $(\mathrm{p}=0.02)$, and showed a trend toward a significant association with 1-hour post-OGTT glucose levels $(\mathrm{p}=0.08)$.

Baseline $25(\mathrm{OH}) \mathrm{D}$ concentrations remained associated with length of gestation after adjustment for HMW-adiponectin in addition to maternal factors $(\beta=0.32, p=0.01$; Table $3 \mathrm{~A})$; however the association with risk of PTB was attenuated ( $p=0.09$; Table 3B). HMW-

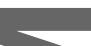
adiponectin was not a significant predictor in the model for PTB $(\mathrm{p}=0.3)$.

\section{Discussion}

To the best of ourknowledge, this is the first study to investigate the relationships between maternal vitamin D levels and cardiometabolic risk factors and pregnancy outcomes in relation to novel adipokines. We found that in overweight or obese pregnant women at high risk of GDM, 25(OH)D concentrations in early pregnancy were inversely associated with cardiometabolic risk factors and had small but significant inverse associations with risk of adverse pregnancy outcomes including GDM. All relationships remained significant after adjusting for relevant maternal factors. However, most associations were attenuated after adjustment for HMW-adiponectin, suggesting a potential mediatory role for this adipokine. 
We found inverse cross-sectional associations between $25(\mathrm{OH}) \mathrm{D}$ concentrations and total cholesterol and triglyceride levels at 12-15 weeks gestation, which persisted after adjusting for maternal factors. This is consistent with a previous study where $25(\mathrm{OH}) \mathrm{D}<75 \mathrm{nmol} / 1 \mathrm{in}$ the first trimester was associated with higher total and LDL cholesterol [35]. In contrast, AlAjlan et al. [36] reported that first trimester 25(OH)D concentrations were positively associated with serum lipids, which was thought to be due to increased lipid synthesis in response to high metabolic demands in early pregnancy [36]. Importantly, this study did not adjust for covariates which may have influenced their results. From a mechanistic perspective, vitamin D may act via the VDR to prevent foam cell formation [37], reduce acetylated LDL cholesterol uptake [38] and regulate serum apolipoprotein A-1 levels [39], thereby enhaneing cholesterol transport and improving lipid profiles [38-40].

We report that $25(\mathrm{OH}) \mathrm{D}$ concentrations were positively associated with HMW-adiponectin, but not with $\mathrm{IL}-6, \mathrm{MCP}-1$, omentin-1, or visfatin after adjustment for maternal factors. Inflammation and adipose tissue failure (characterized by altered adipokine concentrations), have been implicated in the pathophysiology of GDM [41], PTB [42], and preeclampsia [43]. Studies show that omentin-1 has insulin-sensitizing effects [44], while visfatin activates the insulin receptor [45] and MCP-1 deficiency ameliorates insulin resistance [46]. Associations have been reported between $25(\mathrm{OH}) \mathrm{D}$ and these markers in studies of healthy women [47] and women with PCOS [25], but not in pregnant women. Thus, further investigation of these relationships in pregnancy is warranted. Only two previous studies investigated relationships between 25(OH)D and IL-6 in pregnancy, and both reported no association after adjustment for covariates, consistent with our finding $[14,15]$. Similarly, one previous study examined relationships between $25(\mathrm{OH}) \mathrm{D}$ and HMW-adiponectin in pregnancy and reported no association [26]. Disagreement with our finding of a positive association may be due to the 
smaller sample size [26] ( $n=36-37$ compared to $n=102$ in our study); the sampling time-point of 31 weeks gestation (since maternal adiponectin levels decline progressively with advancing gestation [48]); and/or the lack of adjustment for ethnicity (since lower total [49] and HMW-adiponectin [50] have been reported in certain ethnic groups, such as South-Asian women $[49,50])$. The mechanism by which vitamin D may increase adiponectin is thought to be via suppression of the TNF- $\alpha$ gene and the adipose tissue renin-angiotensin system, both of which regulate adiponectin production $[51,52]$. In turn, increased adiponectin may improve insulin sensitivity, lipid profiles, and inflammation, as has been reported in patients with type 2 diabetes, metabolic syndrome, and cardiovascular disease [53, 54].

In longitudinal analyses, early pregnancy $25(\mathrm{OH}) \mathrm{D}$ concentrations (12-15 weeks) were inversely associated with fasting and 1-hour post-OGTT glucose levels and had a small but significant inverse association with risk of GDM at 26-28 weeks. It is important to note that women in this study were at high-risk for GDM, hence our results should be interpreted in light of this. Nevertheless, our findings are similar to previous studies where third trimester $25(\mathrm{OH}) \mathrm{D}$ concentrations were inversely associated with fasting [10, 11, 22, 55-57] and postOGTT glueose levels [58] [11, 56]. Four separate meta-analyses $[5,16,59,60]$ of 7-20 observational studies ( $\mathrm{n}=2100-9200)$, all reported that women with GDM had lower $25(\mathrm{OH}) \mathrm{D}$ levels compared with normoglycemic women, and that GDM risk increased by 40 $60 \%$ in women with vitamin D deficiency $(25(\mathrm{OH}) \mathrm{D}<50 \mathrm{nmol} / \mathrm{l})$.

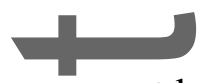

However, recent large-scale studies not included in these meta-analyses reported no relationship between 25(OH)D and post-OGTT glucose levels [57]or GDM risk [19-21]. Most of these studies [19, 20, 57] involved predominantly non-vitamin D-deficient women $(25(\mathrm{OH}) \mathrm{D}>70-132 \mathrm{nmol} / \mathrm{l})$. This may explain their null findings since relationships between vitamin D and glucose metabolism are thought to be more pronounced in vitamin D-deficient 
women $[16,58,59]$. Moreover, most studies examining vitamin D and glycemic outcomes were conducted at 24-38 weeks gestation [5] and $<25 \%$ had adjusted for ethnicity, parity, or smoking status [5]. Here, we show that early pregnancy $25(\mathrm{OH}) \mathrm{D}$ concentrations (12-15 weeks) are associated with fasting and 1-hour glucose and risk of GDM at 26-28 weeks, which persisted after adjusting for these covariates. Vitamin D may reduce GDM risk by elevating intracellular calcium which is vital for $\beta$-cell glycolysis and glucose signaling [60], or by acting on the VDR to upregulate the insulin receptor and facilitate basal- and insulinmediated glucose oxidation and transport [61-65]. Vitamin D may also decrease insulin resistance and GDM risk by downregulating pro-inflammatory cytokines and upregulating anti-inflammatory cytokines [66-68]. While our findings are consistent with most previous literature, we note that our study cohort comprised high-risk women, and that associations between 25(OH)D and GDM risk were small. Large-scale trials are needed to confirm our findings and to establish whether use of vitamin D supplementation may mitigate GDM risk.

Early pregnancy $25(\mathrm{OH}) \mathrm{D}$ concentrations in our study were associated with increased length of gestation, as well as with reduced risk of PTB in adjusted analyses. Observational studies examining vitamin D and PTB have produced conflicting results [4, 21, 69-72]. Nevertheless, our findings are consistent with a meta-analysis of 10 observational studies $(n=10,098)$ reporting a 1.3 times greater risk of $\mathrm{PTB}$ at $25(\mathrm{OH}) \mathrm{D}<50 \mathrm{nmol} / \mathrm{l}$ compared to higher levels [18]. Additionally, we show that $25(\mathrm{OH}) \mathrm{D}$ was associated with length of gestation and PTB risk after adjusting for caesarean section and for the combined effects of age, BMI, ethnicity, parity and smoking status, which has not been shown previously [18]. We were unable to explore sub-categories of PTB (very/moderate/late PTB) due to lack of statistical power; however we report on total length of gestation to show that $25(\mathrm{OH}) \mathrm{D}$ is related to length of gestation even when a defined PTB cut-off ( $<37$ weeks) is not applied. Mechanistically, 
vitamin D deficiency may promote proximal muscle weakness, thus having a possible role in the initiation of early labor [73]. Vitamin D also induces antimicrobial peptides including cathelicidin in placental cells, thereby reducing bacterial infections and infection-induced PTB [18]. The anti-inflammatory properties of vitamin D discussed earlier may also reduce risk of PTB, since chronic inflammation can promote premature membrane rupture and spontaneous labor [74].

Finally, addition of HMW-adiponectin to the multivariable models in our study attenuated most associations, and HMW-adiponectin was the only significant predictor variable in the models for GDM and triglycerides, with a trend toward significance in the model for 1-hour glucose. We speculate that HMW-adiponectin may be a potential mediator of these associations. Human cell studies and animal models show that adiponectin modulates several metabolic processes, and has anti-atherosclerotic, anti-inflammatory, and anti-diabetic properties $[48,75,76]$. Reduced levels of the HMW multimeric form of adiponectin is believed to be pathophysiologically involved in the declining insulin sensitivity that takes place with advancing gestation [48], and has been shown to promote dyslipidemia [53, 54, 77], inflammation [53,54], beta-cell dysfunction [48], and contribute to the development of both GDM $[23,78]$ and PTB [79]. Therefore, it is possible that low HMW-adiponectin levels secondary to vitamin D deficiency may contribute to increased cardiometabolic risks and adverse pregnancy outcomes. However, mechanistic and intervention studies are needed to confirm our finding, and to establish whether vitamin D supplementation increases HMWadiponectin levels and whether this would translate into improved pregnancy outcomes.

Our study has several strengths. This was the first study examining associations between vitamin $\mathrm{D}$ and novel adipokines in pregnancy and the potential mediatory role of these adipokines in relation to cardiometabolic risk and pregnancy outcomes. The sample 
comprised a well-characterized cohort of overweight or obese women at high risk of GDM, which allowed examination of a high-risk group where there was no confounding by comorbidities or medication use. We were able to explore other potential confounding by clinically relevant factors including age, BMI, parity, smoking status, and ethnicity, which have seldom been incorporated in previous studies. Serum $25(\mathrm{OH}) \mathrm{D}$ was measured earlier in pregnancy than most previous studies, which enabled assessment of longitudinal relationships between $25(\mathrm{OH}) \mathrm{D}$ and pregnancy outcomes. We were able to show that associations between $25(\mathrm{OH}) \mathrm{D}$ and cardiometabolic risk and pregnancy outcomes may be mediated by HMWadiponectin, which has not previously been reported.

Limitations include the observational nature of the study which precludes assessment of causality. Beeause this was a secondary post-hoc analysis of data collected for a larger study [27], there was no formal power calculation. Thus, our sample size may have been underpowered to detect associations between 25(OH)D and other maternal outcomes including preeełampsia, and may explain the non-significant trends observed initially for PTB. Participants were overweight or obese women at high risk of GDM, thus results may not be generalizable. The single measurement of $25(\mathrm{OH}) \mathrm{D}$ at $12-15$ weeks gestation meant we could not determine temporal changes in $25(\mathrm{OH}) \mathrm{D}$ or account for potential supplement use which may have altered vitamin D status over the course of pregnancy. We were not able to measure $25(\mathrm{OH}) \mathrm{D}$ using gold-standard liquid chromatography mass-spectrometry, and instead used Diasorin assays which measure both $25(\mathrm{OH}) \mathrm{D}_{2}$ and $25(\mathrm{OH}) \mathrm{D}_{3}$ concentrations. Moreover, because vitamin D is fat-soluble, use of a more sensitive measure of adiposity such as pereentage body fat instead of BMI may have yielded different results. Finally, although we adjusted for multiple confounders, we did not obtain data on vitamin D intake 
from diet or supplements or on sun exposure, seasonality, or sunscreen use, which may have influenced our results.

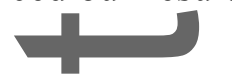

In summary, early pregnancy $25(\mathrm{OH}) \mathrm{D}$ concentrations in overweight or obese pregnant women at high risk of GDM were inversely associated with cardiometabolic risk factors during pregnancy and had small but significant associations with GDM and PTB, after adjustment for covariates. We showed that these associations may be mediated by HMWadiponectin; however the exact mechanism by which $25(\mathrm{OH}) \mathrm{D}$ may interact with HMWadiponectin to influence pregnancy outcomes remains unknown. Further clinical trials and mechanistic studies are needed, with inclusion of: (i) adequate power for pregnancy outcomes as primary endpoints; (ii) adjustment for covariates which affect both vitamin D status and cardiometabolie risk; and (iii) frequent sampling to assess whether temporal changes in $25(\mathrm{OH}) \mathrm{D}$ over the course of pregnancy are related to different clinical outcomes. Such studies may identify "critical windows" of opportunity for measuring and treating vitamin D deficiency and potentially improving pregnancy outcomes.

\section{Acknowledgements}

\subsection{Author contributions}

AM performed data analysis and interpretation and wrote the first draft of the manuscript. HJT and CLH were the lead investigators on the original RCT. SKA, SS, DH and AMA performed laboratory biomarker analyses and contributed to data interpretation and writing and editing the manuscript. NN and NKS contributed to data interpretation and writing and editing the manuscript. BdC, CLH and HJT planned and designed the study and contributed to data interpretation and writing and editing the manuscript. $\mathrm{BdC}$ is the guarantor of this work and, as such, had full access to all the data in the study and takes responsibility for the 
integrity of the data and the accuracy of the data analysis. All authors meet the ICMJE criteria for authorship, and have approved the final version of the manuscript.

\subsection{Funding and support}

As part of a larger sttdy of biomarker analyses, funding for this work was provided by a secondment grant from the Centre for Research Excellence in Polycystic Ovarian Syndrome and a clinical exercise science seed grant from the Institute of Sport, Exercise and Active Living, Victoria University. AM and NN are recipients of the Australian Postgraduate Award provided by Monash University. DH is a recipient of the Australian Postgraduate Award provided by Victoria University. SKA and SS are recipients of postgraduate scholarships provided by the National Health and Medical Research Council (NHMRC) of Australia. BdC is supported by a National Heart Foundation Future Leader Fellowship (100864), the Royal Australasian College of Physicians, and Foundation for High Blood Pressure Research. HT is a NHMRC Practitioner Fellow. We would like to thank all volunteers who took part in the study and the Victoria University lab and technical managers Dr. Samantha Cassar and Tracy Murray for their assistance in conducting laboratory analyses.

5.3. Conflict of interest statement: There are no conflicts of interest to declare.

\section{References}

[1] van Schoor, N. M., Lips, P., Worldwide vitamin D status. Best practice \& research. Clinical endocrinology \& metabolism 2011, 25, 671-680.

[2] Ross, A. C., Manson, J. E., Abrams, S. A., Aloia, J. F., et al., The 2011 report on dietary reference intakes for calcium and vitamin D from the Institute of Medicine: what clinicians need to know. The Journal of ctinical endocrinology and metabolism 2011, 96, 53-58.

[3] Brannon, P. M.,Picciano, M. F., Vitamin D in pregnancy and lactation in humans. Annual review of nutrition 2011, 31, 89-115.

[4] Perez-Ferre, N., Torrejon, M. J., Fuentes, M., Fernandez, M. D., et al., Association of low serum 25-hydroxyvitamin D levels in pregnancy with glucose homeostasis and obstetric and newborn outcomes. Endocrine practice : official journal of the American College of Endocrinology and the American Association of Clinical Endocrinologists 2012, 18, 676-684.

[5] Wei, S. Q., Qi, H. P., Luo, Z. C., Fraser, W. D., Maternal vitamin D status and adverse pregnancy outcomes: a systematic review and meta-analysis. The journal of maternal-fetal \& neonatal medicine 
: the official journal of the European Association of Perinatal Medicine, the Federation of Asia and Oceania Perinatal Societies, the International Society of Perinatal Obstet 2013, 26, 889-899.

[6] Dabrowski, F. A., Grzechocinska, B., Wielgos, M., The role of vitamin D in reproductive health--a Trojan Horse or the Golden Fleece? Nutrients 2015, 7, 4139-4153.

[7] Guillot, X., Semerano, L., Saidenberg-Kermanac'h, N., Falgarone, G., Boissier, M. C., Vitamin D and inflammation. Joint, bone, spine : revue du rhumatisme 2010, 77, 552-557.

[8] Alvarez, J. A., Ashraf, A., Role of vitamin d in insulin secretion and insulin sensitivity for glucose homeostasis. International journal of endocrinology 2010, 2010, 351385.

[9] Evans, K. N., Bulmer, J. N., Kilby, M. D., Hewison, M., Vitamin D and placental-decidual function. Journal of the Society for Gynecologic Investigation 2004, 11, 263-271.

[10] Clifton-Bligh, R. J., McElduff, P., McElduff, A., Maternal vitamin D deficiency, ethnicity and gestational diabetes. Diabetic medicine : a journal of the British Diabetic Association 2008, 25, 678684.

[11] Lau, S. L., Gunton, J. E., Athayde, N. P., Byth, K., Cheung, N. W., Serum 25-hydroxyvitamin D and glycated haemoglobin levels in women with gestational diabetes mellitus. The Medical journal of Australia 2011, 194, 334-337.

[12] Lepsch, J., Eshriqui, I., Farias, D. R., Vaz, J. S., et al., Association between early pregnancy vitamin D status and changes in serum lipid profiles throughout pregnancy. Metabolism: clinical and experimental 2017, 70, 85-97.

[13] Ringrose, J.S., PausJenssen, A. M., Wilson, M., Blanco, L., et al., Vitamin D and hypertension in pregnancy. Clinical and investigative medicine. Medecine clinique et experimentale 2011, 34, E147-154.

[14] Bobbitt, K. R.,Peters, R. M., Li, J., Rao, S. D., et al., Early pregnancy vitamin D and patterns of antenatal inflammation in African-American women. Journal of reproductive immunology 2015, 107, $52-58$.

[15] Xu, L., Lee, M., Jeyabalan, A., Roberts, J. M., The relationship of hypovitaminosis D and IL-6 in preeclampsia. Am J Obstet Gynecol 2014, 210, 149.e141-147.

[16] Zhang, M. X., Pan, G. T., Guo, J. F., Li, B. Y., et al., Vitamin D Deficiency Increases the Risk of Gestational Diabetes Mellitus: A Meta-Analysis of Observational Studies. Nutrients 2015, 7, 83668375.

[17] Arain, N., Mirza, W. A., Aslam, M., Review-Vitamin D and the prevention of preeclampsia: A systematic review. Pakistan journal of pharmaceutical sciences 2015, 28, 1015-1021.

[18] Qin, L.-L., Lu, F.-G., Yang, S.-H., Xu, H.-L., Luo, B.-A., Does Maternal Vitamin D Deficiency Increase the Risk of Preterm Birth: A Meta-Analysis of Observational Studies. Nutrients 2016, 8, 301. [19] Boyle, V. T., Thorstensen, E.B., Mourath, D., Jones, M.B., McCowan, L.M.E., Kenny, L.C. and Baker, P.N. The relationship between 25-hydroxyvitamin D concentration in early pregnancy and pregnancy outcomes in a large, prospective cohort. British Journal of Nutrition 2016, 116, 1409-1415. [20] Rodriguez A., G.-E. R., Basterretxea M., Lertxundi A., Rodriguez-Bernal C., Iniguez C., Rodriguez-Dehli C., Tardon A., Espada M., Sunyer J., and Morales E., Associations of maternal circulating 25-hydroxyvitamin D3 concentration with pregnancy and birth outcomes. BJOG: An International Journal of Obstetrics and Gynaecology 2015, 122, 1695-1704.

[21] Schneuer, F. J., Roberts, C. L., Guilbert, C., Simpson, J. M., et al., Effects of maternal serum 25hydroxyvitamin D concentrations in the first trimester on subsequent pregnancy outcomes in an Australian population. The American journal of clinical nutrition 2014, 99, 287-295.

[22] Haidari, F., Jalali, M. T., Shahbazian, N., Haghighizadeh, M. H., Azadegan, E., Comparison of Serum Levels of Vitamin D and Inflammatory Markers Between Women With Gestational Diabetes Mellitus and Healthy Pregnant Control. Journal of family \& reproductive health 2016, 10, 1-8. [23] Vrachnis, N., Belitsos, P., Sifakis, S., Dafopoulos, K., et al., Role of Adipokines and Other Inflammatory Mediators in Gestational Diabetes Mellitus and Previous Gestational Diabetes Mellitus. International journal of endocrinology 2012, 2012, 12.

[24] Al-Daghri, N. M., Al-Attas, O. S., Alokail, M. S., Alkharfy, K. M., et al., Hypovitaminosis D associations with adverse metabolic parameters are accentuated in patients with Type 2 diabetes 
mellitus: a body mass index-independent role of adiponectin? Journal of endocrinological investigation 2013, 36, 1-6.

[25] Kiyak Caglayan, E., Engin-Ustun, Y., Sari, N., Gocmen, A. Y., et al., Is there association between vitamin D levels, apelin 36, and visfatin in PCOS? Gynecological endocrinology: the official journal of the International Society of Gynecological Endocrinology 2016, 32, 386-389. [26] McManus, R., Summers, K., de Vrijer, B., Cohen, N., et al., Maternal, umbilical arterial and umbilical venous 25 -hydroxyvitamin $\mathrm{D}$ and adipocytokine concentrations in pregnancies with and without gestational diabetes. Clinical endocrinology 2014, 80, 635-641.

[27] Harrison, C. L., Lombard, C. B., Strauss, B. J., Teede, H. J., Optimizing healthy gestational weight gain in women at high risk of gestational diabetes: A randomized controlled trial. Obesity 2013, 21, 904-909.

[28] Teede, H. J.,Harrison, C. L., Teh, W. T., Paul, E., Allan, C. A., Gestational diabetes: development of an early risk prediction tool to facilitate opportunities for prevention. The Australian \& New Zealand journal of obstetrics \& gynaecology 2011, 51, 499-504.

[29] WHO, World Health Organization, Geneva 2000.

[30] Hoffman, L., Nolan, C., Wilson, J. D., Oats, J. J., Simmons, D., Gestational diabetes mellitus-management guidelines. The Australasian Diabetes in Pregnancy Society. The Medical journal of Australia 1998, 169, 93-97.

[31] Gibson-Helm, M., Teede, H., Block, A., Knight, M., et al., Maternal health and pregnancy outcomes among women of refugee background from African countries: a retrospective, observational study in Australia. BMC Pregnancy and Childbirth 2014, 14, 392.

[32] RANZCOG, Royal Australia New Zealand College of Obstetricians and Gynaecologists 2015. [33] Fisher, F. M., Trujillo, M. E., Hanif, W., Barnett, A. H., et al., Serum high molecular weight complex of adiponectin correlates better with glucose tolerance than total serum adiponectin in IndoAsian males. Diabetologia 2005, 48, 1084-1087.

[34] Hara, K. Horikoshi, M., Yamauchi, T., Yago, H., et al., Measurement of the high-molecular weight form of adiponectin in plasma is useful for the prediction of insulin resistance and metabolic syndrome.Diabetes care 2006, 29.

[35] Lepsch, J., Eshriqui, I., Farias, D. R., Vaz, J. S., et al., Association between early pregnancy vitamin D status and changes in serum lipid profiles throughout pregnancy. Metabolism - Clinical and Experimental, 70, 85-97.

[36] Al-Ajlan, A., Krishnaswamy, S., Alokail, M. S., Aljohani, N. J., et al., Vitamin D deficiency and dyslipidemia in early pregnancy. BMC Pregnancy and Childbirth 2015, 15, 314.

[37] Oh, J., Weng, S., Felton, S. K., Bhandare, S., et al., 1,25(OH)2 vitamin d inhibits foam cell formation and suppresses macrophage cholesterol uptake in patients with type 2 diabetes mellitus. Circulation 2009, 120, 687-698.

[38] Al-Daghri, N. M., Alkharfy, K. M., Al-Saleh, Y., Al-Attas, O. S., et al., Modest reversal of metabolic syndrome manifestations with vitamin D status correction: a 12-month prospective study. Metabolism. clinical and experimental 2012, 61, 661-666.

[39] Wehmeier, K. R., Mazza, A., Hachem, S., Ligaray, K., et al., Differential regulation of apolipoprotein A-I gene expression by vitamin D receptor modulators. Biochimica et biophysica acta 2008, $1780,264-273$.

[40] Carbone, L. D., Rosenberg, E. W., Tolley, E. A., Holick, M. F., et al., 25-Hydroxyvitamin D, cholesterol, and ultraviolet irradiation. Metabolism: clinical and experimental 2008, 57, 741-748.

[41] Coskun, A., Ozkaya, M., Kiran, G., Kilinc, M., Arikan, D. C., Plasma visfatin levels in pregnant women with normal glucose tolerance, gestational diabetes and pre-gestational diabetes mellitus. The Journal of Maternal-Fetal \& Neonatal Medicine 2010, 23, 1014-1018.

[42] Mazaki-Tovi, S., Romero, R., Vaisbuch, E., Erez, O., et al., Maternal plasma visfatin in preterm labor. The Journal of Maternal-Fetal \& Neonatal Medicine 2009, 22, 693-704.

[43] Liu, H., Wu, J., Wang, H., Sheng, L., et al., Association of serum omentin-1 concentrations with the presence and severity of preeclampsia. Annals of clinical biochemistry 2015, 52, 245-250. 
[44] Brandt, B., Mazaki-Tovi, S., Hemi, R., Yinon, Y., et al., Omentin, an adipokine with insulinsensitizing properties, is negatively associated with insulin resistance in normal gestation. Journal of perinatal medicine 2015, 43, 325-331.

[45] Chen, M. P., Chung, F. M., Chang, D. M., Tsai, J. C., et al., Elevated plasma level of visfatin/pre-B cell colony-enhancing factor in patients with type 2 diabetes mellitus. The Journal of clinical endocrinology and metabolism 2006, 91, 295-299.

[46] Nio, Y., Yamauchi, T., Iwabu, M., Okada-Iwabu, M., et al., Monocyte chemoattractant protein-1 (MCP-1) defieiency enhances alternatively activated M2 macrophages and ameliorates insulin resistance and fattyliver in lipoatrophic diabetic A-ZIP transgenic mice. Diabetologia 2012, 55, $3350-3358$

[47] Zorlu,M., Kiskac, M., Cakirca, M., Karatoprak, C., et al., Evaluation of the Relation between Vitamin D and Serum Omentin and Vaspin Levels in Women. Experimental and clinical endocrinology \& diabetes : official journal, German Society of Endocrinology [and] German Diabetes Association 2016, 124, 440-443.

[48] Retnakaran, A, Retnakaran, R., Adiponectin in Pregnancy: Implications for Health and Disease. Current Medicinal Chemistry 2012, 19, 5444-5450.

[49] Retnakaran, R., Hanley, A. J., Zinman, B., Does hypoadiponectinemia explain the increased risk of diabetes and cardiovascular disease in South Asians? Diabetes care 2006, 29, 1950-1954.

[50] Retnakaran, R.. Hanley, A. J., Connelly, P. W., Maguire, G., et al., Low serum levels of highmolecular weight adiponectin in Indo-Asian women during pregnancy: evidence of ethnic variation in adiponectin isoform distribution. Diabetes care 2006, 29, 1377-1379.

[51] Vilarrasa, N., Vendrell, J., Maravall, J., Elio, I., et al., Is plasma 25(OH) D related to adipokines, inflammatory cytokines and insulin resistance in both a healthy and morbidly obese population?

Endocrine 2010, 38, 235-242.

[52] Baziar, N., Jafarian, K., Shadman, Z., Qorbani, M., et al., Effect of therapeutic dose of vitamin d on serum adiponectin and glycemia in vitamin d-insufficient or deficient type 2 diabetic patients. Iran 2014, 16, e21458.

[53] Kadowaki, T., Yamauchi, T., Kubota, N., Hara, K., et al., Adiponectin and adiponectin receptors in insulin resistance, diabetes, and the metabolic syndrome. Journal of Clinical Investigation 2006,

$116,1784-1792$.

[54] Menzaghi, C., Trischitta, V., Doria, A., Genetic influences of adiponectin on insulin resistance, type 2 diabetes, and cardiovascular disease. Diabetes 2007, 56, 1198-1209.

[55] El Lithy, A., Abdella, R. M., El-Faissal, Y. M., Sayed, A. M., Samie, R. M. A., The relationship between low maternal serum vitamin $\mathrm{D}$ levels and glycemic control in gestational diabetes assessed by HbA1c levels: an observational cross-sectional study. BMC Pregnancy and Childbirth 2014, 14, 362.

[56] Makgoba, M., Nelson, S. M., Savvidou, M., Messow, C. M., et al., First-trimester circulating 25hydroxyvitamin D levels and development of gestational diabetes mellitus. Diabetes care 2011, 34, 1091-1093

[57] McLeod, D. S., Warner, J. V., Henman, M., Cowley, D., et al., Associations of serum vitamin D concentrations with obstetric glucose metabolism in a subset of the Hyperglycemia and Adverse Pregnancy Outcome (HAPO) study cohort. Diabetic medicine : a journal of the British Diabetic Association 2012, 29, e199-204.

[58] Farrant, H. J., Krishnaveni, G. V., Hill, J. C., Boucher, B. J., et al., Vitamin D insufficiency is common in Indian mothers but is not associated with gestational diabetes or variation in newborn size. European journal of clinical nutrition 2009, 63, 646-652.

[59] Burris, H. H., Rifas-Shiman, M. S. L., Kleinman, K., Litonjua, A. A., et al., Vitamin D Deficiency in Pregnancy and Gestational Diabetes. American journal of obstetrics and gynecology 2012, 207,182.e181-182.e188.

[60] Palomer, X., Gonzalez-Clemente, J. M., Blanco-Vaca, F., Mauricio, D., Role of vitamin D in the pathogenesis of type 2 diabetes mellitus. Diabetes, obesity \& metabolism 2008, 10, 185-197. 
[61] Maestro, B., Campion, J., Davila, N., Calle, C., Stimulation by 1,25-dihydroxyvitamin D3 of insulin receptor expression and insulin responsiveness for glucose transport in U-937 human promonocytic cells. Endocrine journal 2000, 47, 383-391.

[62] Maestro, B., Molero, S., Bajo, S., Davila, N., Calle, C., Transcriptional activation of the human insulin receptor gene by 1,25-dihydroxyvitamin $\mathrm{D}(3)$. Cell biochemistry and function 2002, 20, 227 232.

[63] Maestro B, D N., Carranza MC, Calle C., Identification of a Vitamin D response element in the human insulin receptor gene promoter. Steroid Biochem Mol Biol.. 2003, 84, 223-230.

[64] Dunlop, T. W., Vaisanen, S., Frank, C., Molnar, F., et al., The human peroxisome proliferatoractivated receptor delta gene is a primary target of 1alpha,25-dihydroxyvitamin D3 and its nuclear receptor. Journal of molecular biology 2005, 349, 248-260.

[65] Pilz, S, yan den Hurk, K., Nijpels, G., Stehouwer, C. D., et al., Vitamin D status, incident diabetes and prospective changes in glucose metabolism in older subjects: the Hoorn study. Nutrition, metabolism, and cardiovascular diseases : NMCD 2012, 22, 883-889.

[66] Giulietti, A.gvan Etten, E., Overbergh, L., Stoffels, K., et al., Monocytes from type 2 diabetic patients have a pro-inflammatory profile. 1,25-Dihydroxyvitamin $\mathrm{D}(3)$ works as anti-inflammatory. Diabetes Res Clin Pract 2007, 77, 47-57.

[67] Korf, H., Wenes, M., Stijlemans, B., Takiishi, T., et al., 1,25-Dihydroxyvitamin D3 curtails the inflammatory and T cell stimulatory capacity of macrophages through an IL-10-dependent mechanism. Immunobiology 2012, 217, 1292-1300.

[68] Zhang, Y., Leung, D. Y., Richers, B. N., Liu, Y., et al., Vitamin D inhibits monocyte/macrophage proinflammatory cytokine production by targeting MAPK phosphatase-1. Journal of immunology (Baltimore, Md. : 1950) 2012, 188, 2127-2135.

[69] Baker, A. M., Haeri, S., Camargo, C. A., Jr., Stuebe, A. M., Boggess, K. A., A nested casecontrol study of first-trimester maternal vitamin D status and risk for spontaneous preterm birth. American journal of perinatology 2011, 28, 667-672.

[70] Bodnar, L. M., Platt, R. W., Simhan, H. N., Early-pregnancy vitamin D deficiency and risk of preterm birth subtypes. Obstetrics and gynecology 2015, 125, 439-447.

[71] Dunlop, A.L., Taylor, R. N., Tangpricha, V., Fortunato, S., Menon, R., Maternal micronutrient status and preterm versus term birth for black and white US women. Reproductive sciences (Thousand Oaks, Calif.) 2012,19, 939-948.

[72] Zhu, T., Liu, T. J., Ge, X., Kong, J., et al., High prevalence of maternal vitamin D deficiency in preterm births in northeast China, Shenyang. International journal of clinical and experimental pathology 2015, 8, 1459-1465.

[73] Merewood, A., Mehta, S. D., Chen, T. C., Bauchner, H., Holick, M. F., Association between Vitamin D Deficiency and Primary Cesarean Section. The Journal of clinical endocrinology and metabolism 2009, 94, 940-945.

[74] Liu, N. Q., Hewison, M., Vitamin D, the placenta and pregnancy. Archives of biochemistry and biophysics 2012, 523, 37-47.

[75] Dinca, M., Serban, M.-C., Sahebkar, A., Mikhailidis, D. P., et al., Does vitamin D supplenentation alter plasma adipokines concentrations? A systematic review and meta-analysis of randomized controlled trials. Pharmacological Research 2016, 107, 360-371.

[76] Matsuzawa, Y., Adiponectin: Identification, physiology and clinical relevance in metabolic and vascular disease. Atherosclerosis Supplements 2005, 6, 7-14.

[77] Nawrocki, A. R., Hofmann, S. M., Teupser, D., Basford, J. E., et al., Lack of Association Between Adiponectin Levels and Atherosclerosis in Mice. Arteriosclerosis, Thrombosis, and Vascular Biology 2010, 30, 1159.

[78] Guillemette, L., Allard, C., Lacroix, M., Patenaude, J., et al., Genetics of Glucose regulation in Gestation and Growth (Gen $3 \mathrm{G})$ : a prospective prebirth cohort of mother-child pairs in Sherbrooke, Canada. BMJ open 2016, 6, e010031.

[79] Mazaki-Tovi, S., Romero, R., Vaisbuch, E., Erez, O., et al., DYSREGULATION OF MATERNAL SERUM ADIPONECTIN IN PRETERM LABOR. The journal of maternal-fetal \& neonatal medicine : the official journal of the European Association of Perinatal Medicine, the 
Federation of Asia and Oceania Perinatal Societies, the International Society of Perinatal Obstetricians 2009, 22, 887-904.

Table 1. Sample characteristics:

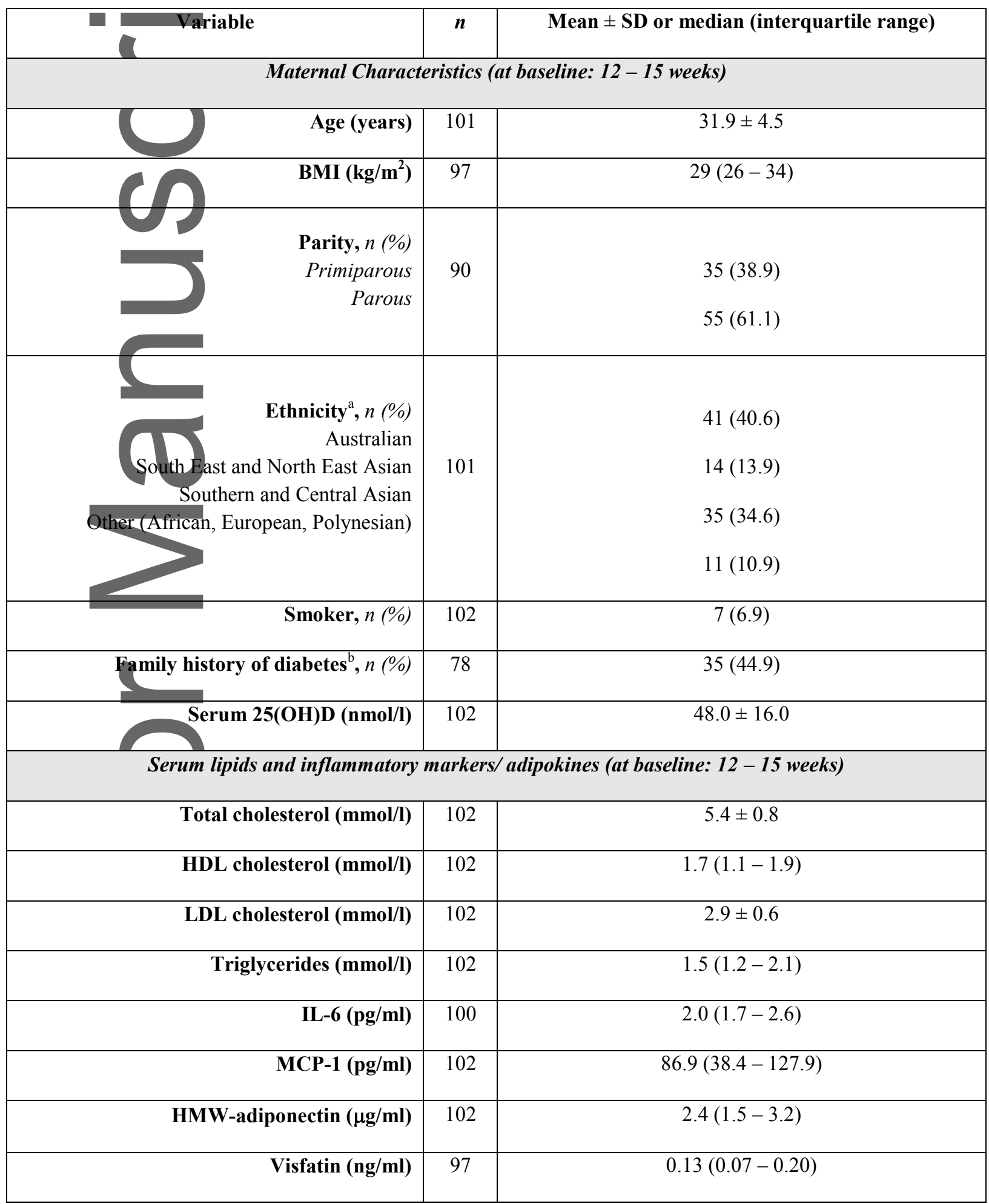

This article is protected by copyright. All rights reserved. 


\begin{tabular}{|c|c|c|}
\hline Omentin-1 (ng/ml) & 99 & $50.0(38.0-68.0)$ \\
\hline \multicolumn{3}{|c|}{ Glycemic Outcomes (at OGTT: $26-28$ weeks) } \\
\hline Fasting glucose- OGTT ${ }^{\mathrm{c}}(\mathrm{mmol} / \mathrm{l})$ & 102 & $4.5(4.2-4.9)$ \\
\hline 1-hour glucose post- OGTT ${ }^{\mathrm{c}}(\mathrm{mmol} / \mathrm{l})$ & 102 & $8.5 \pm 2.3$ \\
\hline 2-hour glucose post ${ }^{\mathrm{c}}(\mathrm{mmol} / \mathrm{l})$ & 102 & $6.7(5.8-7.8)$ \\
\hline Gestational Diabetes Mellitus ${ }^{\mathrm{c}}, n(\%)$ & 102 & $25(24.5)$ \\
\hline \multicolumn{3}{|c|}{ Pregnancy Outcomes (during pregnancy/at delivery) } \\
\hline Pre-eclampsia $^{\mathrm{c}}, n(\%)$ & 102 & $4(3.9)$ \\
\hline Preterm birth $\left(\right.$ gestation $<37$ weeks) $^{\mathrm{c}}, n(\%)$ & 102 & $6(5.9)$ \\
\hline Caesarean section $^{\mathrm{c}}, n(\%)$ & 102 & $25(24.5)$ \\
\hline Length of gestation $^{\mathrm{c}}$ (weeks) & 97 & $39.4(38.4-40.2)$ \\
\hline
\end{tabular}

Data are presented as mean \pm standard deviation and $\mathrm{n}(\%)$, or median (interquartile range) for non-normally distributed variables, unless otherwise specified;

a ethnicity was derived from self-reported country of birth;

${ }^{\mathrm{b}}$ family history refers to first degree relatives only.

${ }^{c}$ all variables measured at 12-15 weeks gestation except OGTT (26-28 weeks), length of gestation, and pregnancy outcomes (during pregnancy/ at delivery);

Abbreviations: 25(OH)D, 25-hydroxyvitamin D; BMI, body mass index; IL-6, interleukin-6; MCP-1, monocytechemoattractant protein-1; HMW, high-molecular weight; HDL/LDL, high-/ low- density lipoprotein; OGTT, oral glucose tolerance test; $\mathrm{C}$-section, caesarean section.

This article is protected by copyright. All rights reserved. 
Table 2. Univariable associations between 25 -hydroxyvitamin D concentrations and cardiometabolic risk factors and pregnancy outcomes:

\begin{tabular}{|c|c|c|c|}
\hline Variable & $n$ & $\begin{array}{l}\text { Correlation coefficient }(r) \text { or } \\
\text { odds ratio }(95 \% \text { CI })\end{array}$ & $p$ \\
\hline \multicolumn{4}{|c|}{ Maternal Characteristics (at baseline: $12-15$ weeks) } \\
\hline Age (years) & 101 & 0.13 & 0.2 \\
\hline BMI $\left(\mathrm{kg} / \mathbf{m}^{2}\right)$ & 97 & -0.15 & 0.1 \\
\hline \multicolumn{4}{|c|}{ Serum lipids and inflammatory markers / adipokines (at baseline: $12-15$ weeks) } \\
\hline Total cholesterol (mmol/l) & 98 & -0.22 & 0.03 \\
\hline HDL cholesterol (mmol/l) & 98 & 0.004 & 0.9 \\
\hline LDL cholesterol (mmol/l) & 98 & -0.07 & 0.5 \\
\hline Triglycerides (mmol/l) & 98 & -0.30 & 0.003 \\
\hline IL-6 (pg/ml) & 100 & -0.20 & 0.048 \\
\hline MCP-1 (pg/ml) & 102 & -0.09 & 0.4 \\
\hline IW-adiponectin $(\mu \mathrm{g} / \mathrm{ml})$ & 102 & 0.27 & 0.007 \\
\hline Visfatin (ng/ml) & 97 & 0.03 & 0.2 \\
\hline Omentin-1 (ng/ml) & 99 & 0.13 & 0.2 \\
\hline \multicolumn{4}{|c|}{ Glycemic outcomes (at OGTT: $26-28$ weeks) } \\
\hline Fasting glucose $^{\mathrm{a}}(\mathrm{mmol} / \mathrm{l})$ & 89 & -0.35 & 0.0008 \\
\hline $\operatorname{cose}$ post-OGTT ${ }^{\mathrm{a}}(\mathrm{mmol} / \mathrm{l})$ & 88 & -0.22 & 0.04 \\
\hline 2-hour glucose post-OGTT ${ }^{\mathrm{a}}(\mathrm{mmol} / \mathrm{l})$ & 89 & -0.16 & 0.1 \\
\hline ational Diabetes Mellitus ${ }^{\mathrm{a}}$ & 102 & $0.97(0.94-0.99)$ & 0.04 \\
\hline \multicolumn{4}{|c|}{ Pregnancy outcomes (during pregnancy / at delivery) } \\
\hline Pre-eclampsia $^{\mathrm{a}}$ & 97 & $1.02(1.00-1.09)$ & 0.6 \\
\hline Length of gestation ${ }^{\mathrm{a}}$ (weeks) & 97 & 0.32 & 0.001 \\
\hline Preterm birth $^{\text {a }}$ (gestation $<37$ weeks) & 97 & $0.95(0.90-1.00)$ & 0.09 \\
\hline Caesarean section $^{\mathrm{a}}$ & 97 & $1.00(0.97-1.03)$ & 0.7 \\
\hline
\end{tabular}

This article is protected by copyright. All rights reserved. 
Data are presented as correlation coefficients for continuous outcome variables or odds ratios with $95 \%$ CI for categorical outcome variables. Non-normally distributed variables were log-transformed to the base 10 to approximate normality prior to analyses;

$\boldsymbol{p}=$ significance of associations with 25-hydroxyvitamin D using Pearson correlations for continuous variables and simple logistic regression for categorical variables;

a all variables measured at 12-15 weeks gestation except OGTT (26-28 weeks), length of gestation, and pregnancy outeomes (during pregnancy/ at delivery);

Abbreviations: BMI, body mass index; IL-6, interleukin-6; MCP-1, monocyte-chemoattractant protein-1; HMW, high-molecular weight; OGTT, oral glucose tolerance test; HDL/LDL, high-/ low- density lipoprotein; GDM, gestational diabetes mellitus.

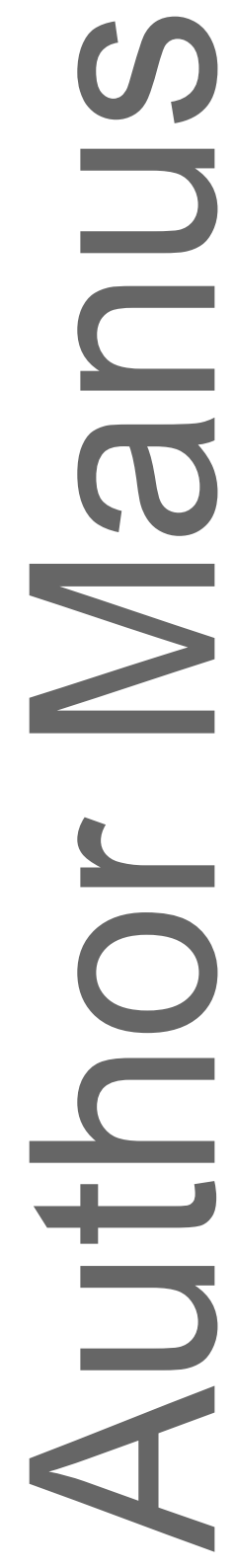

This article is protected by copyright. All rights reserved. 
Table 3. Multiple linear and logistic regression models for associations between 25 -hydroxyvitamin D concentrations and cardiometabolic risk factors and pregnancy outcomes:

\begin{tabular}{|c|c|c|c|c|c|c|c|c|}
\hline \multirow{2}{*}{ Dependent Variable } & \multicolumn{4}{|c|}{ Model 1} & \multicolumn{4}{|c|}{ Model 2} \\
\hline & $\begin{array}{c}\text { Standardized } \\
\qquad \beta\end{array}$ & $\mathbf{R}^{2}$ & $t$ & $p$ & $\begin{array}{c}\text { Standardized } \\
\qquad \beta\end{array}$ & $\mathbf{R}^{2}$ & $t$ & $p$ \\
\hline Total cholesterol (mmol/l) & -0.23 & 0.32 & -2.08 & 0.04 & -0.20 & 0.33 & -1.77 & 0.08 \\
\hline HDL cholesterol (mmol/l) & -0.12 & 0.27 & -1.13 & 0.3 & & & & \\
\hline LDL cholesterol (mmol/l) & -0.03 & 0.19 & -0.26 & 0.8 & & & & \\
\hline Triglycerides (mmol/l) & -0.28 & 0.24 & -2.49 & 0.02 & -0.18 & 0.31 & -1.55 & $0.1^{\mathrm{c}}$ \\
\hline IL-6 (pg/ml) & -0.06 & 0.38 & -0.57 & 0.6 & & & & \\
\hline MCP-1 (pg/ml) & -0.04 & 0.10 & -0.38 & 0.7 & & & & \\
\hline HMW-adiponectin $(\mu \mathrm{g} / \mathrm{ml})$ & 0.25 & 0.30 & 2.32 & 0.02 & - & - & - & - \\
\hline Visfatin (ng/ml) & 0.08 & 0.10 & 0.68 & 0.5 & & & & \\
\hline Omentin-1 (ng/ml) & 0.08 & 0.13 & 0.63 & 0.5 & & & & \\
\hline Fasting glucose $^{\mathrm{a}}(\mathrm{mmol} / \mathrm{l})$ & -0.38 & 0.27 & -3.25 & 0.002 & -0.32 & 0.30 & -2.58 & 0.01 \\
\hline
\end{tabular}

This is the (athor manuscript accepted for publication and has undergone full peer review but has not been through the copyediting, typesetting, pagination and proofrem or ocess, which may lead to differences between this version and the Version of Record. Please cite this article as doi:

$10.1002 / \mathrm{mnn}^{2} \mathrm{r}-100488$.

This article nro cted by copyright. All rights reserved. 


\begin{tabular}{r|ccccc|cccc}
\hline 1-hour glucose post-OGTT & (mmol/l) & -0.26 & 0.30 & -2.32 & 0.02 & -0.17 & 0.32 & -1.37 & 0.2 \\
\hline 2-hour glucose post-OGTT $^{\mathrm{a}}(\mathbf{m m o l} / \mathbf{l})$ & -0.21 & 0.21 & -1.77 & 0.08 & & & & \\
\hline Length of gestation $^{\mathrm{a}}(\mathbf{w e e k s})$ & 0.33 & 0.16 & 2.90 & 0.005 & 0.32 & 0.15 & 2.65 & 0.01 \\
\hline
\end{tabular}

3B. Multiple logistic regression analysis for categorical outcomes

\begin{tabular}{|c|c|c|c|c|c|c|}
\hline \multirow{2}{*}{ Dependent Variable } & \multicolumn{3}{|c|}{ Model 1} & \multicolumn{3}{|c|}{ Model 2} \\
\hline & OR $(95 \% \mathrm{CI})$ & $z$ & $p$ & OR $(95 \% \mathrm{CI})$ & $z$ & $\boldsymbol{P}$ \\
\hline Gestational Diabetes Mellitus $^{\text {a }}$ & $0.96(0.93,0.99)$ & -2.35 & 0.02 & $0.97(0.93-1.00)$ & -1.55 & $0.1^{\mathrm{c}}$ \\
\hline Pre-eclampsia ${ }^{a}$ & $1.05(0.93,1.20)$ & 0.85 & 0.4 & & & \\
\hline Preterm birth $^{\mathrm{a}}$ (gestation $<37$ weeks) & $0.89(0.79,0.99)$ & -2.21 & $0.03^{\mathrm{b}}$ & $0.88(0.77-1.02)$ & -1.74 & 0.08 \\
\hline Caesarean section $^{a}$ & $1.00(0.97,1.04)$ & 0.29 & 0.8 & & & \\
\hline
\end{tabular}

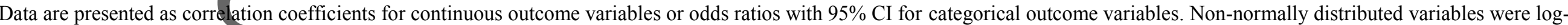
transformed to the base 10 to approximate normality prior to analyses;

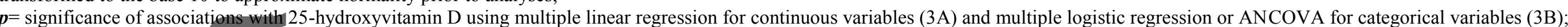
${ }^{a}$ all variables measured at 12-15 weeks gestation except OGTT (26-28 weeks), length of gestation, and pregnancy outcomes (during pregnancy/ at delivery);

${ }^{\mathrm{b}}$ preterm birth was additionally adjusted for caesarean section in both model 1 and model 2 ;

${ }^{c}$ denotes that HMW-adiponectin was a significant predictor in the multivariable model (ie: significantly associated with the outcome).

Model 1: linear and logistie regression models adjusted for maternal factors: age, BMI, parity, ethnicity, and smoking status;

Model 2: linear and logistic regression models adjusted for HMW-adiponectin in addition to maternal factors: age, BMI, parity, ethnicity, and smoking status

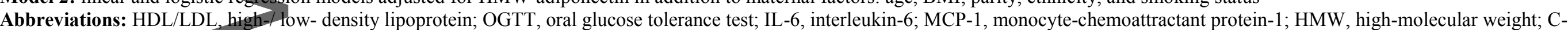

section, caesarean section

This article is protected by copyright. All rights reserved. 


\section{University Library}

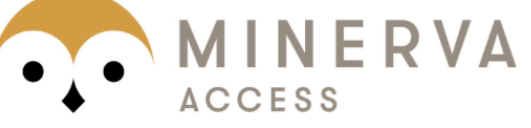

A gateway to Melbourne's research publications

Minerva Access is the Institutional Repository of The University of Melbourne

\section{Author/s:}

Mousa, A;Abell, SK;Shorakae, S;Harrison, CL;Naderpoor, N;Hiam, D;Moreno-Asso, A;Stepto, $\mathrm{NK}$; Teede, HJ;de Courten, B

Title:

Relationship between vitamin D and gestational diabetes in overweight or obese pregnant women may be mediated by adiponectin

Date:

2017-11-01

Citation:

Mousa, A., Abell, S. K., Shorakae, S., Harrison, C. L., Naderpoor, N., Hiam, D., MorenoAsso, A., Stepto, N. K., Teede, H. J. \& de Courten, B. (2017). Relationship between vitamin $D$ and gestational diabetes in overweight or obese pregnant women may be mediated by adiponectin. MOLECULAR NUTRITION \& FOOD RESEARCH, 61 (11), https:// doi.org/10.1002/mnfr.201700488.

Persistent Link:

http://hdl.handle.net/11343/293354 